\title{
Echocardiography Screening for Diagnosis of Latent RHD Using Nurses: Is the Project Feasible for Nepal?
}

\author{
Prakash Raj Regmi ${ }^{1}$, Riju Kafle ${ }^{1}$ \\ ${ }^{1}$ Nepal Heart Foundation, Pulchowk, Lalitpur, Nepal \\ Corresponding Author: Prakash Raj Regmi \\ Nepal Heart Foundation, Pulchowk, Lalitpur, Nepal \\ Email: pregmi68@gmail.com \\ ORCID ID NO: 0000-0002-2197-2672
}

Cite this article as: Regmi P. R., Kafle R. Echocardiography Screening for Diagnosis of Latent RHD Using Nurses: Is the Project Feasible for Nepal? Nepalese Heart Journal 2021: Vol 18(2), 1-5.

Submission date: $6^{\text {th }}$ September, 2021

Accepted date: $5^{\text {th }}$ October, 2021

\begin{abstract}
Rheumatic Heart Disease (RHD) is a preventable disease which occurs years or decades after the onset of Acute Rheumatic Fever (ARF) in childhood. The prevalence of RHD is still high in Nepal, with most cases of latent RHD concentrated in the rural, resource-limited setting. The sequelae of latent RHD cases often manifest decades later, causing a significant burden on the health system. Training of non-experts with simple protocols in such remote setting for screening of latent RHD is showing promising results worldwide. Screening of latent RHD is advocated in RHD endemic areas where early detection by echo screening can alleviate a massive burden on morbidity and mortality in the future. More research is needed to explore this possibility in the context of an endemic country like Nepal to tackle the burden of RHD.
\end{abstract}

Keywords: Latent Rheumatic heart disease, Echocardiography screening, Non-experts

DOI: https://doi.org/10.3126/njh.v18i2.40386

\section{Introduction}

Rheumatic Heart Disease (RHD) is a sequela of Rheumatic Fever (RF), with the progression to valvular heart disease occurring years to decades later after the initial Rheumatic Fever, leading to disabling or fatal complications in cases without earlier intervention. While it was a major health problem in both developed and developing nations, extensive research and intervention have largely reduced the incidence of RHD in the developed countries ${ }^{1}$. However, RHD remains a leading public health problem in developing countries, with devastating effects on children and young adults in their most productive years of life ${ }^{2}$. The 21 st century has shown a lack of research in the area of RHD in developing countries, due to which effective policies to combat RHD have been stalling ${ }^{1,3,4}$.

Clinically silent RHD diagnosed through echocardiographic screening has been termed latent RHD and classified as borderline and definite RHD according to World Heart Federation (WHF) 2012 criteria $^{5,6}$. Latent RHD has a variable course, with late presentation and diagnosis of patients with RHD, being crucial elements for the high morbidity and mortality in low- and middle-income countries ${ }^{6-9}$. Detecting latent RHD cases in high-endemic areas is largely advocated by studies as both borderline and mild definite RHD cases are at substantial risk of progression and should be enrolled in close clinical follow-up. Children with moderate-to-severe latent RHD found by echocardiographic screening should be considered missed clinical cases and treated accordingly ${ }^{8,10}$. In Nepal, there are limited publications on echo screening. A study published in 2016 from eastern Nepal on echocardiography screening has stated the prevalence of latent RHD to be as high as 10.2 per 1000 children. The silent disease was also found to be 5 times more common than symptomatic cases 9 .

Due to its high burden in middle and low-income countries, there has been a growing interest in detecting latent RHD earlier through echocardiography screening ${ }^{4-6,11}$, targeting resource-limited settings for widespread coverage, often using non-experts with simpler echo criteria and portable devices ${ }^{7,12-23}$. While several studies are already pinpointing accurate prevalence of latent RHD with the help of simplified criteria and handheld/portable echo machines ${ }^{16,18,20}$, the possibility of medical intervention with benzathine penicillin altering the progression of the disease such asymptomatic cases is still being researched in trials like an ongoing GOAL Trial in Uganda ${ }^{4,24}$.

\section{Scenario of RHD In Nepal}

Nepal is a low-income country in South East Asia with a population of 29.1 million, with about $79.80 \%$ population living in rural areas. Nepal has an average life expectancy of 70.48 years with a 0.7 physician per 1000 people ratio. The government spends around $5.6 \%$ of the GDP on the health sector ${ }^{25}$. The Human Development Index (HDI) was 0.587 in 2019, at a position of 147 out of 189 countries, with the score in urban areas (0.647) surpassing that of rural areas $(0.561)$ with a large urban-rural gap ${ }^{26}$. 
RHD is considered a significant public health problem in Nepal, especially among children and young adults, despite limited data until the latter half of the 20th century ${ }^{27,28}$. Owing to the overwhelming disease load, Nepal Heart Foundation (NHF) was established in 1988 which initiated community activities on RHD prevention through the "Save the Children's Heart Program" in 1990. Due to the overwhelming demand for heart valve surgery for severe RHD, tertiary care centers used to have a waitlist that crossed a year, necessitating the need for early detection of RHD and also a comprehensive RHD prevention program in Nepal.

Therefore, the Government of Nepal (GoN), Ministry of Health and Population (MoHP) developed a National RF/RHD prevention and control program in $2007 \mathrm{AD}$ and collaborated with the NHF for its implementation. A study done for assessing the effectiveness of the national RHD program had shown promising results ${ }^{29,30}$. This program was discontinued in $2014 \mathrm{AD}$ due to a change in government policy. Instead, GoN initiated free heart valve surgery program to help the advanced RHD cases.

A hospital-based cross-sectional study published in 2016 AD by Laudari et al. in central Nepal, concluded that RHD is a leading cause of heart failure among young populations, with many of them requiring surgery, while most went through a prolonged duration of medical treatment ${ }^{31}$. In another school-based cross-sectional study by Shrestha et al. in 2016 in Sunsari district in Eastern Nepal, the mean incidence was 1.1 per 1000 children per year'. Research conducted by Laudari et al. in 2018 demonstrated a $0.1 \%$ Echo prevalence of RHD on students of Chitwan and Nawalparasi districts of Central Nepal ${ }^{32}$.

The distribution of RHD in Nepal is disproportionate with the highest prevalence in low socio-economic settings in rural areas ${ }^{9,31,32}$. A study conducted in $2018 \mathrm{AD}$ found the prevalence rate of RHD among school-going children of rural Jajarkot more than 7 times higher than in Kathmandu ( 7.12 Vs 0.9 per 1000$)^{33}$. The health system is concentrated in urban areas, leaving the rural areas under-staffed. There are around 190 registered cardiologists in Nepal, most based in urban areas ${ }^{34,35}$. However, the major part of the country is rural, where healthcare is mainly provided by auxiliary health staff ${ }^{36-38}$.

The limited number of cardiologists in Nepal to make an extensive echocardiographic screening for the detection of latent RHD is challenging. In similar limited resource settings like Nepal, task shifting, which is the reallocation of echocardiographic screening to health workers with fewer qualifications using shorter training periods with simpler criteria ${ }^{39}$, is emerging as a promising solution.

Strengthening and expanding such programs may further help prevent progression to severe valvular damage needing surgical intervention. Since echocardiography screening of RHD is important in the early diagnosis of RHD and its management, exploring options for increasing its use in resources limited settings might aid in improving the health outcome in the future ${ }^{9,29}$.

NHF has initiated the END RHD CAMPAIGN NEPAL in 2019 with an objective to reduce the burden of RHD in Nepal by $50 \%$ by the year 2030.For achieving this target a comprehensive RHD control program is needed which should include echo screening of children in large scale.

\section{Echo screening of RHD using non-experts in Nepal}

RHD screening in high-prevalence areas is recommended to detect people who might benefit from follow-up or further evaluation for intervention ${ }^{19,22-23}$. An effective training of non-experts can help in estimating the true prevalence of RHD in the community, and find cases of mild RHD for early treatment and prevention of clinical complications ${ }^{7}$. Emerging research to establish the benefit of providing secondary prophylaxis to all patients with latent RHD4, might further benefit an RHD high-endemic country like Nepal, if there is a well-managed and operative echo screening system in place.

The following factors will need to be determined for an expanded latent RHD detecting echo screening system: feasibility of training the non-experts, the target audience, devices that can be used in rural settings, assessment of adequate training, and use of simplified echo criteria for diagnosis of latent RHD 3 .

a) Feasibility and assessment of training with simplified criteria in non-experts (e.g. Paramedics and nurses):

Training non-experts has been successfully implemented for other aspects of secondary prophylaxis such as delivering Benzathine Penicillin G (BPG) in the RF/RHD control Program. Effective training and support had ensured that over $90 \%$ of paramedics who had earlier refused to inject BPG due to fear, agreed ${ }^{30}$.

The feasibility of training non-expert health workers in a resource-limited setting has been a keenly studied option all over the world. One such study of an 8-week training program in Fiji, designed to train health workers without any prior experience in focused echocardiography for RHD screening, concluded that such training is feasible in settings with limited resources ${ }^{12}$. Another study done from the same country which consisted of a week-long workshop, followed by 2 weeks of supervised field experience demonstrated that nurses can follow a protocol to undertake rheumatic heart disease echocardiography in a developing country with fair accuracy ${ }^{13}$.

An RHD screening in Uganda performed by nurses trained on handheld echocardiography (HAND) using a simplified screening approach had reasonable sensitivity and specificity when compared with the reference standard portable echocardiography (STAND) ${ }^{15}$.

Another study conducted in New Caledonia, a territory with a high prevalence of RHD, used focused cardiac ultrasound (FCU) as a reference approach for RHD screening in a school children population by mobilizing non-expert staff ( 2 nurses with specific training) using a pocket-sized echocardiography machine with a simplified set of echocardiographic criteria. It concluded that FCU by non-experts using pocket devices is feasible and yields acceptable sensitivity and specificity for RHD detection when compared with the standard approach, which could be utilized in a resource-limited setting ${ }^{14}$.

Various studies in Mozambique ${ }^{20}$, Uganda ${ }^{16}$, Brazil $^{18}$ have also utilized simplified criteria for echocardiography screening to determine RHD prevalence.

A major concern is that the 2012 WHF criteria for echocardiographic diagnosis of $\mathrm{RHD}^{5}$, are far too complicated for nonexpert training. WHF diagnostic guidelines also require continuous wave (CW) Doppler, which is not currently available with HAND ${ }^{5,15}$. Thus, a simplified approach for HAND using combined criteria of mitral regurgitation jet length $\geq 1.5 \mathrm{~cm}$ or any aortic insufficiency was explored, which showed a high sensitivity for definite RHD21, and had acceptable sensitivity and specificity for non-experts ${ }^{15}$.

In a more recent study in 2019, Nunes et al., have identified the five key components of the WHF criteria that have the strongest predictive value for definite RHD and introduced a simpler criterion that requires hand-held ultrasound without spectral Doppler ${ }^{7,24}$.

While this simplified score is relatively new and awaits validity, it is highly accurate in recognizing definite RHD and will also be easier to use for rural screenings. It can classify children with latent RHD into low, intermediate, or high-risk groups based on echocardiographic features at diagnosis, which will potentially help explain individual disease progression and outcome to the child and family. Furthermore, it might potentially also help influence the need for secondary prophylaxis ${ }^{7,24}$.

b) Target audience: Under the NHF guidelines, the target audience for screening by echocardiography in Nepal are the school-going children of age group five to 15 years ${ }^{29,30}$.

c) Devices used in rural settings: Compared to echocardiographic examination, the accuracy of cardiac auscultation is poorer40-42 RHD screening programs using portable echocardiography or handheld machines with simplified criteria for screening in remote areas have consistently shown an acceptable value for RHD screening ${ }^{16-19}$. 


\begin{tabular}{|c|c|}
\hline Definite RHD (either A, B, C, or D) & Definite RHD (either A, B, C, or D) \\
\hline Age $\leq 20$ years & Age $>20$ years \\
\hline $\begin{array}{l}\text { A. Pathological MR and at least two } \\
\text { morphological features of RHD of the } \\
\text { MV }\end{array}$ & $\begin{array}{l}\text { A. Pathological MR and at least two } \\
\text { morphological features of RHD of the } \\
\text { MV }\end{array}$ \\
\hline B. MS mean gradient $\geq 4 \mathrm{mmHg}$ & B. MS mean gradient $\geq 4 \mathrm{mmHg}$ \\
\hline $\begin{array}{l}\text { C. Pathological AR and at least two } \\
\text { morphological features of RHD of the } \\
\text { AV }\end{array}$ & $\begin{array}{l}\text { C. Pathological AR and at least two } \\
\text { morphological features of RHD of the } \\
\text { AV }\end{array}$ \\
\hline $\begin{array}{l}\text { D. Borderline disease of both the MV } \\
\text { and AV }\end{array}$ & $\begin{array}{l}\text { D. Borderline disease of both the MV } \\
\text { and } A V\end{array}$ \\
\hline Borderline RHD (either A, B, or C) & $\begin{array}{l}\text { Borderline Not Applicable to } \\
\text { Those Age }>20 \text { Years }\end{array}$ \\
\hline \multicolumn{2}{|l|}{$\begin{array}{l}\text { A. At least } 2 \text { morphological features } \\
\text { of RHD of the MV without } \\
\text { pathological MR or MS }\end{array}$} \\
\hline \multicolumn{2}{|l|}{ B. Pathological MR } \\
\hline \multicolumn{2}{|l|}{ C. Pathological AR } \\
\hline Pathological MR & Pathological AR \\
\hline Seen in two views & Seen in two views \\
\hline In at least one view, jet length $\geq 2 \mathrm{~cm}$ & In at least one view, jet length $\geq 1 \mathrm{~cm}$ \\
\hline $\begin{array}{l}\text { Velocity } \geq 3 \mathrm{~m} / \mathrm{s} \text { for one complete } \\
\text { envelope }\end{array}$ & Velocity $\geq 3 \mathrm{~m} / \mathrm{s}$ in early diastole \\
\hline $\begin{array}{l}\text { Pan-systolic jet in at least one } \\
\text { envelope }\end{array}$ & $\begin{array}{l}\text { Pan-systolic jet in at least one } \\
\text { envelope }\end{array}$ \\
\hline MV Morphological Features & AV Morphological Features \\
\hline $\begin{array}{l}\text { AMVL thickening } \geq 3 \mathrm{~mm} \text { (age } \leq 20 \\
\text { years), } \geq 4 \mathrm{~mm} \text { (age } 21-40 \text { years), } \\
\geq 5 \mathrm{~mm} \text { (age }>40 \text { years) }\end{array}$ & Irregular or focal thickening \\
\hline Chordal thickening & Coaptation defect \\
\hline Restricted leaflet motion & Restricted leaflet motion \\
\hline $\begin{array}{l}\text { Excessive leaflet tip motion during } \\
\text { systole }\end{array}$ & Leaflet prolapse \\
\hline
\end{tabular}

RHD, rheumatic heart disease; $M R$, mitral regurgitation; $M V$, mitral valve; MS, mitral stenosis; $A R$, aortic regurgitation; $A V$, aorlic valve; $A M V L$, anterior mitral valve leaflet.

Figure 1: World Heart Federation criteria for diagnosing RHD

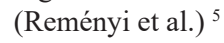

\begin{tabular}{lccccc}
\hline Variable & $\beta$-coefficient & SE & $Z$ value & $\boldsymbol{p}$-value & Points \\
\hline Mitral Valve & & & & & \\
Anterior leaflet thickening & 2.941 & 0.597 & 4.922 & $<0.0001$ & 3 \\
Excessive leaflet tip motion & 3.102 & 0.543 & 5.716 & $<0.0001$ & 3 \\
Regurgitation jet length $\geq 2 \mathrm{~cm}$ & 5.601 & 0.705 & 7.941 & $<0.0001$ & 6 \\
Aortic Valve & & & & & \\
Irregular focal thickening & 4.460 & 0.970 & 4.597 & $<0.0001$ & 4 \\
Any regurgitation & 4.794 & 0.718 & 6.679 & $<0.0001$ & 5 \\
\hline & & & & & \\
& & & & &
\end{tabular}
et al. $)^{7}$

Figure 2: Simplified echocardiography scoring system (Nunes

\section{Limitation And Possibilities}

Latent RHD has a variable natural history according to their environmental exposure to streptococcal infections, genetics, age at diagnosis, and other factors. While echocardiography screening can detect RHD in asymptomatic individuals, the efficacy of initiation of secondary prophylaxis in such latent borderline RHD cases is unproved and is still being studied. However, screening of latent RHD is advocated in RHD endemic areas where early detection by echo screening can alleviate a massive burden on morbidity and mortality in the future.

Furthermore, for training to be effective, accurate detection of latent RHD must be explored after optimal training for nurses and paramedics with the development of a structured training curriculum and standardized competency testing. If the screening is done by paramedics in remote setting where experts are in scarcity, then referral of the patient to experts can be done. The definite RHD cases which are then diagnosed can be sent for secondary prophylaxis. The borderline RHD cases could be evaluated in detail using STAND. Thus, a collaboration between the health ministry, heart foundation, cardiologists, physicians, and other health staff involved in the screening program will be required, along with telemedicine wherever necessary.

\section{Conclusion}

Presently in Nepal, echocardiography screening program is possible only if we recruit non-experts after training them in focused echocardiography with the use of simplified echo criteria for detecting latent RHD. This tool should be evaluated for its efficacy in rural settings. The experience from similar parts of the world shows that it is a feasible and necessary task for a country like Nepal where the RHD burden is high. This program would help us better understand the prevalence in a largely unscreened rural population for the formulation of National Health Programs on RHD better targeted to cater to the most affected demographics. With further evidence, this could also be used effectively to provide secondary prophylaxis and largely prevent severe valve damage in RHD cases.

Training non-experts (e.g. nurses and paramedics) to perform RHD screening using simplified protocols in the rural setting is a more immediate cost-effective fix in a resource-constrained setting like Nepal. Expanding a national RF/RHD program to include costeffective and efficient options for widespread latent RHD screening in this area is the need of the hour.

\section{References}

1. Carapetis JR, Beaton A, Cunningham MW, Guilherme L, Karthikeyan G, Mayosi BM, Sable C, Steer A, Wilson N, Wyber R, Zühlke L. Acute rheumatic fever and rheumatic heart disease. Nat Rev Dis Primers. 2016 Jan 14;2:15084. doi: 10.1038/nrdp.2015.84. PMID: 27188830; PMCID: PMC5810582.

2. Expert Consultation on Rheumatic Fever and Rheumatic Heart Disease, Weltgesundheits organisation, editors. Rheumatic fever and rheumatic heart disease: report of a WHO Expert Consultation, Geneva, 29 October - 1 November 2001 ; [WHO Expert Consultation on Rheumatic Fever and Rheumatic Heart Disease]. Geneva: WHO; 2004. 122 p. (WHO technical report series).

3. Soesanto AM, Suastika LOS. Echocardiography Screening for Latent Rheumatic Heart Disease: What Can We Do in Indonesia? Frontiers in Surgery. 2020;7:46.

4. Beaton A, Okello E, Engelman D, Grobler A, Scheel A, DeWyer A, Sarnacki R, Omara IO, Rwebembera J, Sable C, Steer A. Determining the impact of Benzathine penicillin G prophylaxis in children with latent rheumatic heart disease (GOAL trial): Study protocol for a randomized controlled trial. Am Heart J. 2019 Sep;215:95-105. doi: 10.1016/j. ahj.2019.06.001. Epub 2019 Jun 8. PMID: 31301533.

5. Reményi B, Wilson N, Steer A, Ferreira B, Kado J, Kumar K, Lawrenson J, Maguire G, Marijon E, Mirabel M, Mocumbi AO, Mota C, Paar J, Saxena A, Scheel J, Stirling J, Viali S, Balekundri VI, Wheaton G, Zühlke L, Carapetis J. World 
Heart Federation criteria for echocardiographic diagnosis of rheumatic heart disease--an evidence-based guideline. Nat Rev Cardiol. 2012 Feb 28;9(5):297-309. doi: 10.1038/ nrcardio.2012.7. PMID: 22371105; PMCID: PMC5523449.

6. Zühlke L, Engel ME, Lemmer CE, van de Wall M, Nkepu S, Meiring A, et al. The natural history of latent rheumatic heart disease in a 5 year follow-up study: a prospective observational study. BMC Cardiovascular Disorders. 2016 Feb 19;16(1):46.

7. Nunes MCP, Sable C, Nascimento BR, Lima EM, da Silva JLP, Diamantino AC, Oliveira KKB, Okello E, Aliku T, Lwabi P, Colosimo EA, Ribeiro ALP, Beaton AZ. Simplified Echocardiography Screening Criteria for Diagnosing and Predicting Progression of Latent Rheumatic Heart Disease. Circ Cardiovasc Imaging. 2019 Feb;12(2):e007928. doi: 10.1161/ Circimaging.118.007928. PMID: 30704283.

8. Zühlke L, Engel ME, Karthikeyan G, Rangarajan S, Mackie P, Cupido B, Mauff K, Islam S, Joachim A, Daniels R, Francis V, Ogendo S, Gitura B, Mondo C, Okello E, Lwabi P, Al-Kebsi MM, Hugo-Hamman C, Sheta SS, Haileamlak A, Daniel W, Goshu DY, Abdissa SG, Desta AG, Shasho BA, Begna DM, ElSayed A, Ibrahim AS, Musuku J, Bode-Thomas F, Okeahialam BN, Ige O, Sutton C, Misra R, Abul Fadl A, Kennedy N, Damasceno A, Sani M, Ogah OS, Olunuga T, Elhassan HH, Mocumbi AO, Adeoye AM, Mntla P, Ojji D, Mucumbitsi J, Teo K, Yusuf S, Mayosi BM. Characteristics, complications, and gaps in evidence-based interventions in rheumatic heart disease: the Global Rheumatic Heart Disease Registry (the REMEDY study). Eur Heart J. 2015 May 7;36(18):1115-22a. doi: 10.1093/eurheartj/ehu449. Epub 2014 Nov 25. PMID: 25425448; PMCID: PMC4422972.

9. Shrestha NR, Karki P, Mahto R, Gurung K, Pandey N, Agrawal K, Rothenbühler M, Urban P, Jüni P, Pilgrim T. Prevalence of Subclinical Rheumatic Heart Disease in Eastern Nepal: A School-Based Cross-sectional Study. JAMA Cardiol. 2016 Apr 1;1(1):89-96. doi: 10.1001/jamacardio.2015.0292. PMID: 27437661.

10. Beaton A, Aliku T, Dewyer A, Jacobs M, Jiang J, Longenecker CT, Lubega S, McCarter R, Mirabel M, Mirembe G, Namuyonga J, Okello E, Scheel A, Tenywa E, Sable C, Lwabi P. Latent Rheumatic Heart Disease: Identifying the Children at Highest Risk of Unfavorable Outcome. Circulation. 2017 Dec 5;136(23):2233-2244. doi: 10.1161/ CIRCULATIONAHA.117.029936. Epub 2017 Sep 27. PMID: 28972003; PMCID: PMC5716883.

11. Saxena A, Zühlke L, Wilson N. Echocardiographic Screening for Rheumatic Heart Disease: Issues for the Cardiology Community. gh. 2013 Sep 1;8(3):197.

12. Engelman D, Kado JH, Reményi B, Colquhoun SM, Watson C, Rayasidamu SC, Steer AC. Teaching focused echocardiography for rheumatic heart disease screening. Ann Pediatr Cardiol. 2015 May-Aug;8(2):118-21. doi: 10.4103/0974-2069.157024. PMID: 26085762; PMCID: PMC4453179.

13. Engelman D, Kado JH, Reményi B, Colquhoun SM, Watson C, Rayasidamu SC, Steer AC. Teaching focused echocardiography for rheumatic heart disease screening. Ann Pediatr Cardiol. 2015 May-Aug;8(2):118-21. doi: 10.4103/0974-2069.157024. PMID: 26085762; PMCID: PMC4453179

14. Mirabel M, Bacquelin R, Tafflet M, Robillard C, Huon B, Corsenac P, de Frémicourt I, Narayanan K, Meunier JM, Noël B, Hagège AA, Rouchon B, Jouven X, Marijon E. Screening for rheumatic heart disease: evaluation of a focused cardiac ultrasound approach. Circ Cardiovasc Imaging. 2015 Jan;8(1):e002324. doi: 10.1161/CIRCIMAGING.114.002324. PMID: 25567654.

15. Ploutz M, Lu JC, Scheel J, Webb C, Ensing GJ, Aliku T, Lwabi P, Sable C, Beaton A. Handheld echocardiographic screening for rheumatic heart disease by non-experts. Heart. 2016 Jan;102(1):35-9. doi: 10.1136/heartjnl-2015-308236. Epub 2015 Oct 5. PMID: 26438784.

16. Beaton A, Lu JC, Aliku T, Dean P, Gaur L, Weinberg J, Godown J, Lwabi P, Mirembe G, Okello E, Reese A, ShresthaAstudillo A, Bradley-Hewitt T, Scheel J, Webb C, McCarter R, Ensing G, Sable C. The utility of handheld echocardiography for early rheumatic heart disease diagnosis: a field study. Eur Heart J Cardiovasc Imaging. 2015 May;16(5):475-82. doi: 10.1093/ehjci/jeu296. Epub 2015 Jan 5. PMID: 25564396; PMCID: PMC4542771.

17. Ali S, Awadallah H, Al Hamim A, Al Hussein H, Al Amin Al Sunni M, Bushari T, Ahmed MH. Handheld echocardiography for screening and control of rheumatic heart disease study in Gezira state, Sudan: a double approach model. Cardiovasc Diagn Ther. 2018 Aug;8(4):500-507. doi: 10.21037/ cdt.2018.07.04. PMID: 30214865; PMCID: PMC6129838.

18. Nascimento BR, Sable C, Nunes MCP, Diamantino AC, Oliveira KKB, Oliveira CM, Meira ZMA, Castilho SRT, Santos JPA, Rabelo LMM, Lauriano KCA, Carmo GAL, Tompsett A, Ribeiro ALP, Beaton AZ; PROVAR (Rheumatic Valve Disease Screening Program) Investigators. Comparison Between Different Strategies of Rheumatic Heart Disease Echocardiographic Screening in Brazil: Data From the PROVAR (Rheumatic Valve Disease Screening Program) Study. J Am Heart Assoc. 2018 Feb 14;7(4):e008039. doi: 10.1161/JAHA.117.008039. PMID: 29444774; PMCID: PMC5850205.

19. Beaton A, Okello E, Lwabi P, Mondo C, McCarter R, Sable C. Echocardiography screening for rheumatic heart disease in Ugandan schoolchildren. Circulation. 2012 Jun 26;125(25):3127-32. doi: 10.1161/Circulation AHA.112.092312. Epub 2012 May 24. PMID: 22626741.

20. Mirabel M, Celermajer DS, Ferreira B, Tafflet M, Perier MC, Karam N, Mocumbi AO, Jani DN, Sidi D, Jouven X, Marijon E. Screening for rheumatic heart disease: evaluation of a simplified echocardiography-based approach. Eur Heart J Cardiovasc Imaging. 2012 Dec;13(12):1024-9. doi: 10.1093/ ehjci/jes077. Epub 2012 Apr 19. PMID: 22518053.

21. Lu JC, Sable C, Ensing GJ, Webb C, Scheel J, Aliku T, Lwabi P, Godown J, Beaton A. Simplified rheumatic heart disease screening criteria for handheld echocardiography. J Am Soc Echocardiogr. 2015 Apr;28(4):463-9. doi: 10.1016/j. echo.2015.01.001. Epub 2015 Feb 7. PMID: 25660669.

22. Steer AC, Kado J, Wilson N, Tuiketei T, Batzloff M, Waqatakirewa L, Mulholland EK, Carapetis JR. High prevalence of rheumatic heart disease by clinical and echocardiographic screening among children in Fiji. J Heart Valve Dis. 2009 May;18(3) 327-35; discussion 336. PMID: 19557993.

23. Carapetis JR, Beaton A, Cunningham MW, Guilherme L, Karthikeyan G, Mayosi BM, Sable C, Steer A, Wilson N, Wyber R, Zühlke L. Acute rheumatic fever and rheumatic heart disease. Nat Rev Dis Primers. 2016 Jan 14;2:15084. doi: 10.1038/nrdp.2015.84. PMID: 27188830; PMCID: PMC5810582. 
24. Longenecker CT. Echo Screening for Rheumatic Heart Disease. Circ Cardiovasc Imaging. 2019 Feb;12(2):e008818. doi: 10.1161/CIRCIMAGING.118.008818. PMID: 30704284.

25. United Nations. World statistics pocketbook 2020 edition [Internet]. UN; 2014 [cited 2020 Oct 10]. (World Statistics Pocketbook (Ser. V)). Available from: https://www.un-ilibrary. org/content/books/9789210566575

26. United Nations Development Programme. 2020. Nepal Human Development Report 2020 Beyond Graduation: Productive Transformation and Prosperity. Singha Durbar, Kathmandu, Nepal, Government of Nepal, 2020

27. World Health Organization. Community control of rheumatic heart diseases in developing countries : (continued front wer no. 37) = lutte contre le rhumatisme cardiaque au niveau de la collectivité dans les pays en développement : (Suite du REH N ${ }^{\circ}$ 37). Weekly Epidemiological Record = Relevé épidémiologique hebdomadaire. 1981;56(38):299-303.

28. Pandey MR, Ghimire M. Prevalence of various types of heart diseases in kathmandu- a six years survey of admitted cases. j Nepal Med Assoc [Internet]. 2003 Jan.1 [cited 2021Oct.10];13(39):37-46. Available from: https://www.jnma. com.np/jnma/index.php/jnma/article/view/1138

29. Regmi PR. Comprehensive Approach To Rheumatic Fever and Rheumatic Heart Disease Prevention and Control: The Nepalese Model. Nepalese Heart J. [Internet]. 2016 Aug. 27 [cited 2021 Oct. 10];13(2):3-10. Available from: https://www. nepjol.info/index.php/NHJ/article/view/15555

30. Regmi PR, Wyber R. Prevention of Rheumatic Fever and Heart Disease: Nepalese Experience. Global Heart. 2013;8(3):24752. DOI: http://doi.org/10.1016/j.gheart.2013.08.001

31. Laudari S, Subramanyam G. A study of spectrum of rheumatic heart disease in a tertiary care hospital in Central Nepal. IJC Heart \& Vasculature. 2017 Jun 1;15:26-30.

32. Laudari S, Tiwari KK, Pazdernik M, Sharma SK. Rheumatic Heart Disease Screening Among School Children in Central Nepal. JACC: Case Reports. 2019 Aug;1(2):218-20.

33. Regmi PR, Shakya U, Adhikaree A, Paudyal JR. Rheumatic Heart Disease in school going children: A cross-sectional epidemiological profile of Jajarkot, Nepal. Nepalese Heart J. [Internet]. 2019 Nov. 14 [cited 2021 Oct. 10];16(2):1-4. Available from: https://www.nepjol.info/index.php/NHJ/article/ view/26293

34. Vaidya A. Tackling cardiovascular health and disease in Nepal: epidemiology, strategies and implementation. Heart Asia. 2011 Jan 1;3(1):87-91. doi: 10.1136/heartasia-2011-010000. PMID: 27326001; PMCID: PMC4898564.

35. Record from Cardiac Society of Nepal,2021 (Unpublished)

36. Shrestha C, Bhandari R. Insight into Human Resources for Health Status in Nepal. Health Prospect [Internet]. 2018 Jul. 22 [cited 2021 Oct. 10];11:40-1. Available from: https://www. nepjol.info/index.php/HPROSPECT/article/view/7431

37. Ministry of Health and Population Government of Nepal (2010) Nepal Health Sector Programme- Implementation Plan II (NHSP-IP 2) 2010 - 2015 Final Draft 18 March 2010

38. Human Resource Information Center, Ministry of Health and Population, Report, 2008

39. World Health Organization. Task Shifting: Rational redistribution of tasks amongst health workforce teams: Global recommendations and guidelines. Geneva: WHO; 2008
40. Rothenbühler M, O'Sullivan CJ, Stortecky S, Stefanini GG, Spitzer E, Estill J, Shrestha NR, Keiser O, Jüni P, Pilgrim T. Active surveillance for rheumatic heart disease in endemic regions: a systematic review and meta-analysis of prevalence among children and adolescents. Lancet Glob Health. 2014 Dec;2(12):e717-26. doi: 10.1016/S2214-109X(14)70310-9. PMID: 25433627.

41. Reddy A, Jatana SK, Nair M. Clinical Evaluation Versus Echocardiography in the Assessment of Rheumatic Heart Disease. Med J Armed Forces India. 2004 Jul;60(3):255-8. doi: 10.1016/S0377-1237(04)80058-3. Epub 2011 Jul 21. PMID: 27407645 ; PMCID: PMC4923052.

42. Godown J, Lu JC, Beaton A, Sable C, Mirembe G, Sanya R, Aliku T, Yu S, Lwabi P, Webb CL, Ensing GJ. Handheld echocardiography versus auscultation for detection of rheumatic heart disease. Pediatrics. 2015 Apr;135(4):e939-44. doi: 10.1542/peds.2014-2774. Epub 2015 Mar 16. PMID: 25780068 . 